\title{
A contribuição do líder à educação corporativa e percepção de aprendizado e desenvolvimento dos empregados: o caso de uma empresa prestadora de serviços financeiros
}

\author{
Silvia Gattai ${ }^{1}$ \\ Rodrigo Cunha da Silva ${ }^{2}$ \\ André Laizo dos Santos ${ }^{3}$
}

\section{Resumo}

Este estudo tem por objetivo analisar o papel das lideranças na educação corporativa e o conseqüente impacto na percepção do aprendizado e desenvolvimento dos empregados. Essa investigação foi realizada por meio do levantamento de dados secundários no banco de dados da pesquisa das Melhores Empresas para você Trabalhar de 2010. Para efeito deste artigo, no universo de organizações onde os líderes são responsáveis pelo processo de aprendizagem dos empregados, foi selecionada uma empresa prestadora de serviços financeiros , com o objetivo de analisar as características do papel e as competências requeridas do líder no desenvolvimento das ações de educação corporativa. Essa relação foi constatada a partir do processo de conciliação teórica entre construtos apresentados no artigo e a base teórica utilizada na seleção das afirmativas respondidas pelos empregados.

\begin{abstract}
This study aims to examine the role of leaders in corporate education and the consequent impact on the learning and development perception of the employees. This research was done through research with secondary data in the database of the Best Companies to Work for 2010's survey. For purpose of this article, the universe of organizations where the leaders are responsible for the learning process of the employees, it was selected a company providing financial services, with the aim of analyzing the characteristics of the role and skills required of a leader in the development of education initiatives corporate. This relationship was found from the process of the theoretical conciliation between constructs presented in the article and the theoretical basis used in the selection of statements answered by the employees.
\end{abstract}

Artigo recebido em 21/02/2011

Aprovado em 13/04/2011

\footnotetext{
${ }^{1}$ Professora Associada da Faculdade de Gestão e Serviços na Universidade Metodista de São Paulo e doutoranda em Administração de Empresas pela Faculdade de Economia, Administração e Contabilidade da Universidade de São Paulo- FEA/USP.

${ }^{2}$ Graduado em administração de empresas pela Universidade Cidade de São Paulo - UNICID e mestrando em Administração de Empresas pela Faculdade de Economia, Administração e Contabilidade da Universidade de São Paulo- FEA/USP. ${ }^{3}$ Possui graduação e é mestrando em Administração de Empresas pela Faculdade de Economia, Administração e
Contabilidade da Universidade de São Paulo- FEA/USP, também exerce a função de consultor de empresas.
} 
A contribuição do líder à educação corporativa e percepção de aprendizado e desenvolvimento dos empregados: o caso de uma empresa prestadora de serviços financeiros

\section{Introdução}

Ao refletir sobre a contribuição dos líderes ao processo de educação corporativa de uma organização, são abordadas duas dimensões para análise dessa contribuição, aquela relacionada ao papel de liderança e outra que diz respeito ao perfil de competências de liderança. Nesse sentido, surgem as seguintes perguntas: Quais as diferenças e semelhanças entre papel de liderança e competências de liderança? Porque é importante analisar as duas dimensões quando se pesquisa sobre a contribuição dos líderes ao processo de educação corporativa?

Pode-se afirmar que o papel de liderança é uma visão mais genérica e conseqüência de uma prática recorrente, ou seja, com uma característica cultural, que gera uma expectativa de papel no grupo onde se insere.

Por outro lado, o perfil de competências de liderança ou de gestão é definido pela organização, como explicitação das suas expectativas sobre os comportamentos, conhecimentos, habilidades, valores esperados de seus líderes. O perfil de competências é construído de forma planejada e estruturada e pode reforçar o papel já existente ou forçar sua mudança.

Nesse sentido, segundo Schein (1989), os líderes bem preparados transmitem a sensação de compromisso com o grupo, a partir do seu discernimento; motivação e habilidade para se comunicar. Reconhece-se, portanto, que a liderança pode influenciar uma redefinição cognitiva nos indivíduos, articulando e produzindo novas visões e conceitos; desde que desenvolva sua habilidade para criar um sentimento de envolvimento e participação.

A liderança tem sido estudada em termos de características individuais e comportamentais, modelos de integração e regras de boa relação e influência nos subordinados (YUKL e VAN FLEET, 1992). Esta relação é importante porque o chefe exerce influencia sobre o subordinado, sendo ele o responsável por solucionar conflitos, esclarecer dúvidas e pontuar o passo a passo a ser seguido pela equipe de trabalho. Assim, o comportamento de um superior possui a capacidade de influenciar seus subordinados ao ponto de terem bons ou péssimos desempenhos, e ainda, de auxiliar no sentimento de satisfação ou insatisfação do trabalhador (YUKL e VAN FLEET, 1992).

Dessa forma, o líder apresenta-se como agente fundamental na estrutura dos modelos de educação corporativa que busquem o compromisso dos empregados com o seu 
aprendizado e desenvolvimento profissional em consonância com os objetivos estratégicos da organização.

A pesquisa empírica do objeto em análise, que é o papel das lideranças na educação corporativa e o conseqüente impacto na percepção do aprendizado e desenvolvimento dos empregados é realizada por meio de uma investigação com pesquisa secundária em banco de dados das Melhores Empresas para você Trabalhar de 2010.

\section{Referencial teórico}

Nesta seção, é apresentado o referencial teórico que aborda o conceito de educação corporativa e da contribuição dos líderes nesse processo.

\subsection{O processo de educação corporativa}

Segundo Éboli (2004), a educação corporativa é o processo estruturado de formação e desenvolvimento dos indivíduos que trabalham na organização, processo esse que possui como principal diretriz para escolha e desenvolvimento de ações de educação dentro e fora da organização o perfil de competências individuais desejado pela empresa para que possa manter suas competências e realizar suas estratégias. Nesse sentido, a educação corporativa é a função organizacional que alinha competências da empresa e competências individuais, gerando assim, por um lado uma vantagem competitiva para a empresa e, por outro, maior empregabilidade para os indivíduos que nela trabalham.

Entende-se que o processo de Educação Corporativa, na medida em que forma, prepara, desenvolve, especializa o profissional pessoal, técnica e gerencialmente contribui, ao longo do processo educativo, para além do desenvolvimento do indivíduo no desempenho de seu papel profissional, facilitando o desenvolvimento de consciência individual sobre a importância e contribuição de seu trabalho para a empresa; a análise crítica e visão integradora da realidade e finalmente preparando o profissional para transformar informação em conhecimento relevante para o seu enriquecimento intelectual e do nível de desempenho no seu trabalho e em sua vida. 
A contribuição do líder à educação corporativa e percepção de aprendizado e desenvolvimento dos empregados: o caso de uma empresa prestadora de serviços financeiros

\subsection{O papel e responsabilidades de liderança que contribuem ao processo de educação corporativa}

Para Moreno (1975), papel é a forma como o indivíduo funciona e se expressa no momento específico em que reage a uma situação específica, na qual outras pessoas ou objetos estão envolvidos. Como esse funcionamento é recorrente ele gera uma expectativa nas pessoas com relação a alguns comportamentos da pessoa que desempenha o papel que o autor denomina expectativa de papel. Portanto, é um meio de auto expressão que é aprendido e desenvolvido nas relações interpessoais. Nesse sentido, é possível afirmar que o papel é um fenômeno cultural, pois é construído ao longo do tempo, em grupo, gerando uma visão coletiva (expectativa de papel) sobre como funciona. É um padrão cultural (SCHEIN, 1986), como o papel de pai, esposa, professor, padre, filho, irmão, e outros papéis que fazem parte de uma determinada cultura. Não há papéis solitários, assim como não há líder sem liderados, nem pai sem filho ou professor sem aluno. Os papéis são complementares. Dessa forma, no processo de aprendizagem do papel, a influência da complementaridade é enorme, ou seja, aprende-se a ser líder, sendo liderado.

Outro aspecto importante relacionado ao exercício do papel é que os papéis que um determinado indivíduo desempenha em sua vida possuem uma base comum, o denominado núcleo do Eu. Como conseqüência, o indivíduo apresenta aspectos do exercício de um determinado papel que desempenha em outros papéis. Pode-se citar como exemplo, alguém que tenha o papel de pai muito desenvolvido pode, de forma inconsciente, atuar como pai em situações profissionais onde deve desempenhar o papel de líder. Finalmente, situações diferenciadas entre si, podem necessitar de uma pessoa um mesmo papel, é o caso do papel de articulador que pode ser exercido na escola, no sindicato e no trabalho.

Com base nessa teoria dos papéis, é possível afirmar que os líderes nas organizações, em todos os níveis, possuem um papel específico relacionado ao processo de educação corporativa que é o papel de líder educador.

Nesse sentido, é possível afirmar que os líderes, nas organizações, desempenham um papel que contribui positivamente para o desenvolvimento do processo de educação corporativa (ÉBOLI, 2004). Esse papel relaciona-se a atuar junto às equipes de trabalho e aos indivíduos de forma a contribuir para a formação, desenvolvimento e fortalecimento do perfil de competências esperado de cada um dos integrantes da equipe de trabalho. As ações 
relacionadas a esse papel são realizadas no próprio ambiente de trabalho e dizem respeito a orientar, esclarecer, valorizar, reconhecer, explicar e outras ações que possibilitam ao liderado a aprendizagem do papel profissional. Há também uma expectativa quanto a ações relacionadas à criação e fortalecimento de uma cultura organizacional que facilite o compartilhamento do conhecimento e a aprendizagem.. Existem momentos que são especialmente característicos de situações de educação corporativa conduzidas pelos líderes. Pode-se citar alguns desses momentos: treinamento em serviço, diálogos para avaliação de desempenho; diálogos sobre novas idéias e conclusões dadas pelo liderado; explicações sobre estratégias, metas, valores, cultura da organização (NONAKA e TAKEUCHI, 1997); diálogos sobre a importância do trabalho do liderado no contexto da organização

Segundo Mintzberg (2005) o papel de "gestor que engaja" que os líderes podem e devem desempenhar possibilita que as pessoas tenham o melhor desempenho possível e descubram novas capacidades. Nesse papel, os líderes ajudam outras pessoas que desenvolvem produtos e entregam serviços a serem importantes na organização. Trabalham em redes e não “ se sentam no topo”, dessa forma, ao estimular e trabalhar nessas redes profissionais, provocam o surgimento de soluções estratégicas. Outra expectativa com relação a esse papel é de que os líderes compreendam que a formulação e implementação de soluções são doís processos que não podem estar separados e conduzidos por diferentes grupos e pessoas. No papel de "líder engajador" deve estimular o aparecimento da energia positiva que existe nas pessoas e grupos que trabalham e assim criar uma visão positiva sobre o lugar onde trabalham. Finalmente, para Mintzberg, liderar é uma crença na capacidade das pessoas baseada no respeito que há por elas.

Para Senge (2000), são líderes, todos aqueles que desempenham um papel dentro das organizações que possibilite a existência de uma tensão criativa, ou seja, uma energia que é gerada quando os indivíduos e grupos, na organização, possuem uma visão comum sobre uma determinada conclusão, decisão, solução de um problema que ele denomina "verdade" a respeito da realidade atual. São líderes também aqueles que possibilitam às pessoas a criação de seu futuro. Para Senge há três tipos de liderança: os líderes de linha em nível local que são responsáveis pelo trabalho que é realizado em nível local e tem autoridade para promover mudanças nesse trabalho, por exemplo, gerentes de fábrica ou gerentes de uma equipe de vendas. São eles que realizam experimentos que testam as conseqüências práticas de novas idéias e abordagens. O outro tipo de líder são os líderes de redes que, pela natureza de seu 
A contribuição do líder à educação corporativa e percepção de aprendizado e desenvolvimento dos empregados: o caso de uma empresa prestadora de serviços financeiros

trabalho penetra em todas as partes da organização, por exemplo, profissionais de T\&D, Supervisores de Produção ou de Vendas, que "espalham a semente" de novas atividades e novas práticas. Finalmente, os líderes executivos que criam um ambiente propício para a aprendizagem e a inovação, principalmente, liderando pelo exemplo.

Para Meister (1994), o apoio do CEO da organização é fundamental ao sucesso do processo de educação corporativa. Tal apoio ocorre quando ele utiliza parte de seu tempo para criar parcerias com universidades, outras empresas que possam auxiliar no processo ou quando aproveita oportunidades para declarar publicamente que a educação corporativa é uma ferramenta estratégica que contribui para a manutenção da competitividade da organização. Também possibilita a criação de uma cultura de compartilhamento das melhores práticas. Nesse caso, considera-se o CEO como um líder executivo, liderando pelo exemplo (SENGE, 2000).

Vários autores apresentam o papel de coach, como uma dimensão importante, em todos os níveis de liderança, relacionado à contribuição ao desenvolvimento profissional de pessoas e grupos; ao fortalecimento e transformação da cultura da organização, aos processos de mudança organizacional e ao processo de educação corporativa, (RODRIGUES DA SILVA, 2005; COWAN, 1999; GIL, 2001).

Nesse sentido a definição de coach é o gestor ou profissional que assume um compromisso, na organização, de apoiar as pessoas que pretendem alcançar um determinado resultado (GIL, 2001).

Segundo Cowan (2002), as responsabilidades relacionadas ao desempenho desse papel, especialmente, em processos de mudança organizacional são: 1. Acompanhar o desempenho e dar feed back, reforçando o comportamento esperado e identificando comportamentos ineficazes e sugerindo alternativas de ação. 2. Observar e responder as oportunidades de coaching, estando atento aos comportamentos, ações e feed back que indiquem a necessidade coaching. 3. Adequar o estilo de coach, com base no perfil de quem será orientado e nas características da situação.Nesse sentido, considerar as habilidades, experiências, estilo de trabalho, entre outros fatores do orientado. É importante levar em consideração os prazos, recursos, complexidade e impacto da tarefa, logística e prioridades da organização, ou seja, as circunstâncias. 4. Encorajamento, isto é, encorajar a iniciativa e a independência e oferecer suporte e orientação, perguntando/estimulando sobre idéias, ações e 
soluções; fornecendo experiência, conhecimento e direção; equilibrando o estímulo e o auxílio.

\subsection{As competências de liderança e sua contribuição ao processo de educação corporativa}

Quando as competências de líderes educadores são apresentadas é importante relembrar, por um lado, a definição das competências necessárias aos sujeitos atuantes numa determinada organização que está relacionada à análise da história, cultura, objetivos estratégicos, competências da organização. Por outro lado, relembrar as dimensões do papel do líder educador apresentadas nesse trabalho: coach e gestor engajador, atuam por exemplo, facilitando o treinamento on the job.

Pesquisas realizadas em três empresas brasileiras por Oderich (2005), apontam para um perfil de competências gerenciais que são: liderança; saber lidar com pessoas; trabalho em equipe; capacidade de energizar pessoas; visão sistêmica da empresa e seu negócio; trabalhar com a mudança. Nessas empresas esse perfil é visto como importante para que os gestores tenham uma atuação eficaz que alinhe as pessoas em torno do eixo estratégico da empresa que também deve ser um objetivo do processo de educação corporativa.

A partir das pesquisas sobre papel e competências dos líderes/gestores que facilitam e fortalecem o processo de educação corporativa é possível concluir que papel de liderança e competências do líder são dimensões que se completam, nessa análise. A educação corporativa tem nos líderes, em todos os níveis hierárquicos da organização, uma base fundamental ao seu desenvolvimento. Se, de um lado, a área de educação corporativa planeja e desenvolve ações de educação estruturadas, que visam alinhar as competências das pessoas e as competências da organização, por outro lado, os líderes, no dia a dia, por meio de atividades como: coach, treinamento on the job, atuação como modelo/exemplo, diálogo constante e outras práticas,

Essa situação é essencial na criação e fortalecimento de uma cultura de aprendizagem, fundamental para o sucesso da educação corporativa, bem como para o alinhamento entre competências das pessoas e eixo estratégico da organização. 
A contribuição do líder à educação corporativa e percepção de aprendizado e desenvolvimento dos empregados: o caso de uma empresa prestadora de serviços financeiros

Senge (1998) declara que o processo de aprendizagem na organização dá-se oferecendo condições concretas para que as pessoas aprendam a criar sua própria realidade, auxiliando-as a compreender o contexto em que vivem e com ele interagir por elas próprias.

Nesse sentido, Tannenbaum (1997) destaca a importância do papel do ambiente de aprendizagem para as organizações, e propõem uma série de fatores que contribuem o seu desenvolvimento, dentre os quais podem se destacar o suporte dos líderes no suporte ao aprendizado e desenvolvimento profissional dos empregados.

Dessa forma, será estudado o papel e as competências do líder na educação corporativa de uma empresa prestadora de serviços financeiros, além da provável relação entre a percepção do suporte oferecido pelo líder à percepção de aprendizado e desenvolvimento profissional dos demais empregados da organização.

\section{Procedimentos metodológicos}

De acordo com informações obtidas no banco de dados da pesquisa das Melhores Empresas Para Você Trabalhar de 2010, que apresenta dados sobre 545 organizações, quando foram perguntadas se adotavam a prática em que os líderes e gestores se responsabilizavam pelos processos de aprendizagem dos empregados, $45 \%$ delas informaram que sim, e a prática abrangia todos os empregados, $16 \%$ para parte e $39 \%$ disseram que não adotavam essa prática. Embora a maior parte dos respondentes tenha respondido que adotam a prática, merece atenção o fato de 39\% das organizações desse levantamento informarem não adotarem nenhuma ação com essa intenção.

Para efeito desse artigo, no universo de organizações onde os líderes são responsáveis pelo processo de aprendizagem dos empregados foi selecionada uma empresa, com o objetivo de analisar as características do papel e as competências requeridas do líder no desenvolvimento das ações de educação corporativa, além de evidenciar a relação entre a percepção dos empregados sobre o seu aprendizado e desenvolvimento profissional com o suporte oferecido pela liderança.

Os dados utilizados são referentes às respostas de 292 empregados da organização deste estudo que em 2010 participou de uma pesquisa de clima organizacional na qual podiam participar organizações com mais de 100 empregados e cinco anos de operação em território 
nacional ou internacional e que procuravam se destacar em termos de práticas de gestão de pessoas e clima organizacional. Na amostra considerada não havia empregados com posições de chefia. Os dados foram tabulados e serão apresentados a seguir na seção de análise dos resultados.

Foram escolhidas nove das sessenta e quatro assertivas presentes no questionário dessa pesquisa, sete relacionadas ao papel e competência de coach relacionado ao suporte da liderança à realização do trabalho e aprendizado, e duas à percepção sobre o aprendizado e desenvolvimento proporcionado pelo trabalho. $\mathrm{O}$ questionário utilizou a escala Likert de 5 pontos (de 1-discordo totalmente até 5-concordo totalmente).

Quanto às práticas de gestão de pessoas a serem analisadas, na mesma instituição onde foram coletados os dados dos empregados respondentes, há a disposição para os pesquisadores interessados um acervo de materiais com detalhamentos das políticas e práticas de gestão de pessoas, os cadernos de evidências, que são enviados pelas áreas de recursos humanos dessas empresas. Estes são documentos elaborados, paralelamente, a um questionário quantitativo, no qual as organizações participantes da pesquisa utilizaram para evidenciar suas políticas e práticas de gestão de pessoas. Foram realizadas estatísticas descritivas e análise conteúdo

Para averiguar $\mathrm{o}$ impacto dessas ações sobre a percepção do aprendizado e desenvolvimento dos empregados e sua possível relação com o suporte e coach oferecido pelas lideranças da organização, foi utilizada a técnica estatística bivariada de correlação de Spearman.

\section{Análise dos Resultados}

Nesta seção os resultados são descritos e analisados, conforme os passos do delineamento do estudo apresentados na seção anterior.

É importante ressaltar que a utilização de bancos de dados sobre organizações como fonte secundária de pesquisa exige que haja uma análise e conciliação entre os conceitos abordados no artigo e a base teórica que suporta a pesquisa na organização. Na Tabela 1 , na seção de análise dos resultados, são apresentadas as assertivas utilizadas para levantar as percepções dos empregados sobre as ações de coach ou suporte dos líderes e sobre o 
A contribuição do líder à educação corporativa e percepção de aprendizado e desenvolvimento dos empregados: o caso de uma empresa prestadora de serviços financeiros

aprendizado e desenvolvimento no trabalho. Os autores deste artigo entendem que as assertivas escolhidas refletem alguns aspectos inerentes à competência de coach dos líderes e aprendizado no trabalho, porém não contempla todos os aspectos relacionados a esses construtos.

\subsection{A empresa foco do estudo}

A organização estudada, denominada neste trabalho como Omega, atualmente com cerca de 2.500 empregados, foi fundada em meados dos anos 60, com base em uma ação cooperada entre bancos que buscavam informações rápidas e seguras para dar suporte às decisões de crédito. A atividade principal era centralizar os serviços de confecção de ficha cadastral única, compartilhada por todos os bancos associados, com redução de custos administrativos para os bancos e cidadãos.

$\mathrm{Na}$ década de 90 , a organização começou a expandir sua atuação ao fornecer informações e análise para todos os segmentos da economia e para empresas de todos os portes. Boa parte da evolução ocorrida na organização, principalmente na última década, deve-se à estratégia adotada sobre as micro, pequenas e médias empresas.

Essas empresas precisam de informações baratas e seguras para decisões de crédito, antes privilégio somente de grandes corporações. As informações fornecidas ajudam as empresas a vender e a comprar, diminuindo os riscos comuns a esses negócios, facilitando cerca de 4 milhões de negócios por dia, para 400 mil clientes diretos e indiretos.

Em meados dos anos 2000, uma organização estrangeira adquiriu o controle acionário da empresa Omega. Essa organização é líder mundial no fornecimento de serviços de informação, marketing e gerenciamento de crédito a organizações e consumidores, com o objetivo de auxiliá-los a gerenciar riscos e benefícios de decisões comerciais e financeiras.

Com a aquisição de $70 \%$ de suas ações por essa empresa estrangeira, a Omega passou a integrar uma empresa global, o que trouxe novas perspectivas de atuação. Um após a fusão, a mesma organização passou por um processo de revisão e de atualização de sua visão, missão e valores, de forma a alinhá-los à estratégia mundial da organização matriz e de expandir o foco de negócios para toda a América Latina. Esses conceitos foram amplamente divulgados e disseminados por meio de diversas ações. Nesse cenário, processos relacionados à gestão de pessoas foram importantes para essa transição, no entanto, não será discutido o 
papel da gestão de pessoas no processo de fusão e aquisição dessas empresas, sim o papel das lideranças no processo de educação corporativa.

\subsection{O Modelo de gestão de pessoas da Omega}

A Omega fundamenta a prática de gestão de pessoas em seu sistema de desenvolvimento humano e organizacional. A dinâmica da estrutura está fundamentada em dois pilares principais: liderança e cultura organizacional, ilustrado pela Figura 1. Para a empresa, a figura abaixo não representa o organograma da área, mas seu modelo de gestão:

O modelo objetiva entender as pessoas de forma avançada, integrando o desenvolvimento profissional ao desenvolvimento pessoal e tem como pressuposto o indivíduo indivisível, o equilíbrio entre vida pessoal e trabalho e entre emoção e razão. De um lado, dois processos garantem o desenvolvimento profissional: planejamento de pessoas e educação corporativa. Do outro, dois processos estimulam o empregado no desenvolvimento pessoal: qualidade de vida e desenvolvimento sustentável.

Figura 1- Modelo de gestão de pessoas da Omega

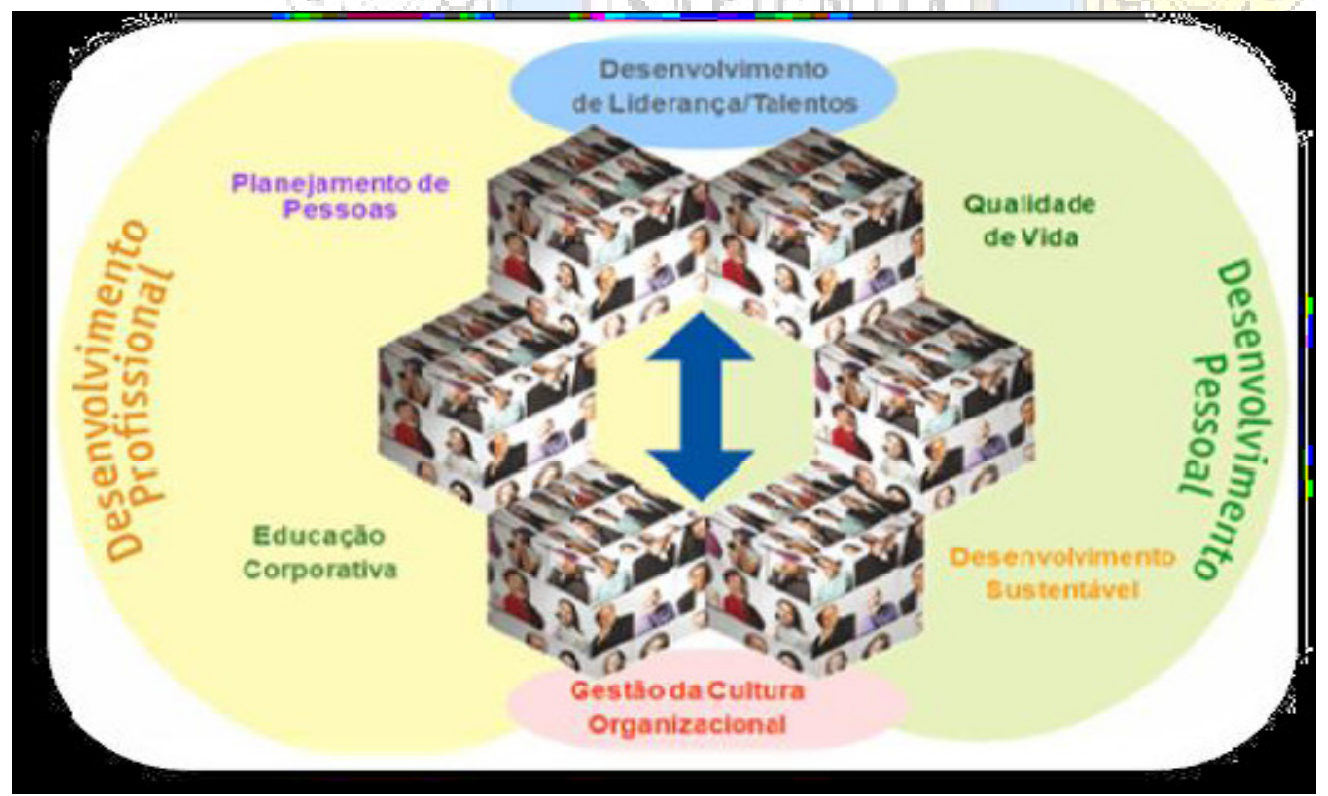

ReCaPe - Revista de Carreiras e Pessoas. São Paulo, V. 01, n.01 Mai/Jun/Jul/Ago 2011 
A contribuição do líder à educação corporativa e percepção de aprendizado e desenvolvimento dos empregados: o caso de uma empresa prestadora de serviços financeiros

\subsection{A Educação Corporativa na Omega}

O processo de educação corporativa é representado, principalmente, por meio das áreas de treinamento e educação corporativa e desenvolvimento de liderança que compõem a área de desenvolvimento humano da empresa, com atuação de cerca de 14 profissionais.

Os programas educacionais oferecidos pela Omega compreendem atividades de aprendizado, realizadas de forma presencial e a distância, visando complementar as ações que geram desenvolvimento pessoal e profissional: Para isso, foram estruturadas quatro escolas para atender os objetivos traçados pelo modelo de educação corporativa da organização, que são conforme o Quadro 1 a escola de artes, escola de formação e idiomas, escola de negócios e escola de liderança

\section{Quadro 1- Descrição das escolas do modelo de educação corporativa da Omega}

\section{Escola de Artes}

- Visa incentivar a qualidade de vida no âmbito corporativo, contribuindo para a melhoria do clima organizacional, por meio de ações que ampliam o conhecimento cultural, desenvolvem habilidades e integram pessoas.

\section{Escola de Formação e Idiomas}

- Os conteúdos relacionados à formação acadêmica visam promover ações educacionais, por meio de subsídio ou cursos in company, de forma a preparar ou dar continuidade à formação acadêmica dos profissionais. Quanto à formação técnica: as ações buscam promover o desenvolvimento de competências para a melhoria do desempenho na área de atuação. Já para formação em idiomas, essa escola visa promover cursos destinados a desenvolver o uso dos idiomas: inglês, espanhol e português na escrita, leitura e conversação.

\section{Escola de Negócios}

- São ações focadas na geração e no aprimoramento de conhecimentos relacionados aos focos de atuação da Omega:

\section{Escola de Liderança}

- Visa promover a mentalidade de liderança em todos os níveis da organização, por meio de ações de desenvolvimento das competências relacionadas às dimensões do Líder 3D (Gestor, Educador e Transformador)- 
Ao analisar a estruturação do modelo de educação corporativa da organização, notase o papel fundamental que o desenvolvimento das competências ligadas às lideranças possui para o seu adequado funcionamento.

A liderança, na Omega, é baseada no conceito do Líder 3D, expressão criada pela organização. De acordo ela, o termo 3D está relacionado às dimensões do líder como gestor, educador e transformador. O conceito de 3D define um líder que busca o equilíbrio entre as três dimensões, pois:

- Gera resultados por meio do gerenciamento de pessoas, processos e projetos;

- Foca no desenvolvimento humano;

- Transforma o ambiente interno e externo.

Com base no conceito do Líder 3D, todos os líderes participam de um programa de educação contínua, no qual o ponto de partida é o programa de introdução ao Líder 3D, que busca desenvolver os líderes, por meio de um processo de aprendizado participativo, o conceito de líder como agente do processo educacional, conforme a Figura 2 a seguir:

\section{Figura 2- Programa de desenvolvimento do Líder 3D}

\section{Programa de Desenvolvimento do Líder 3D}

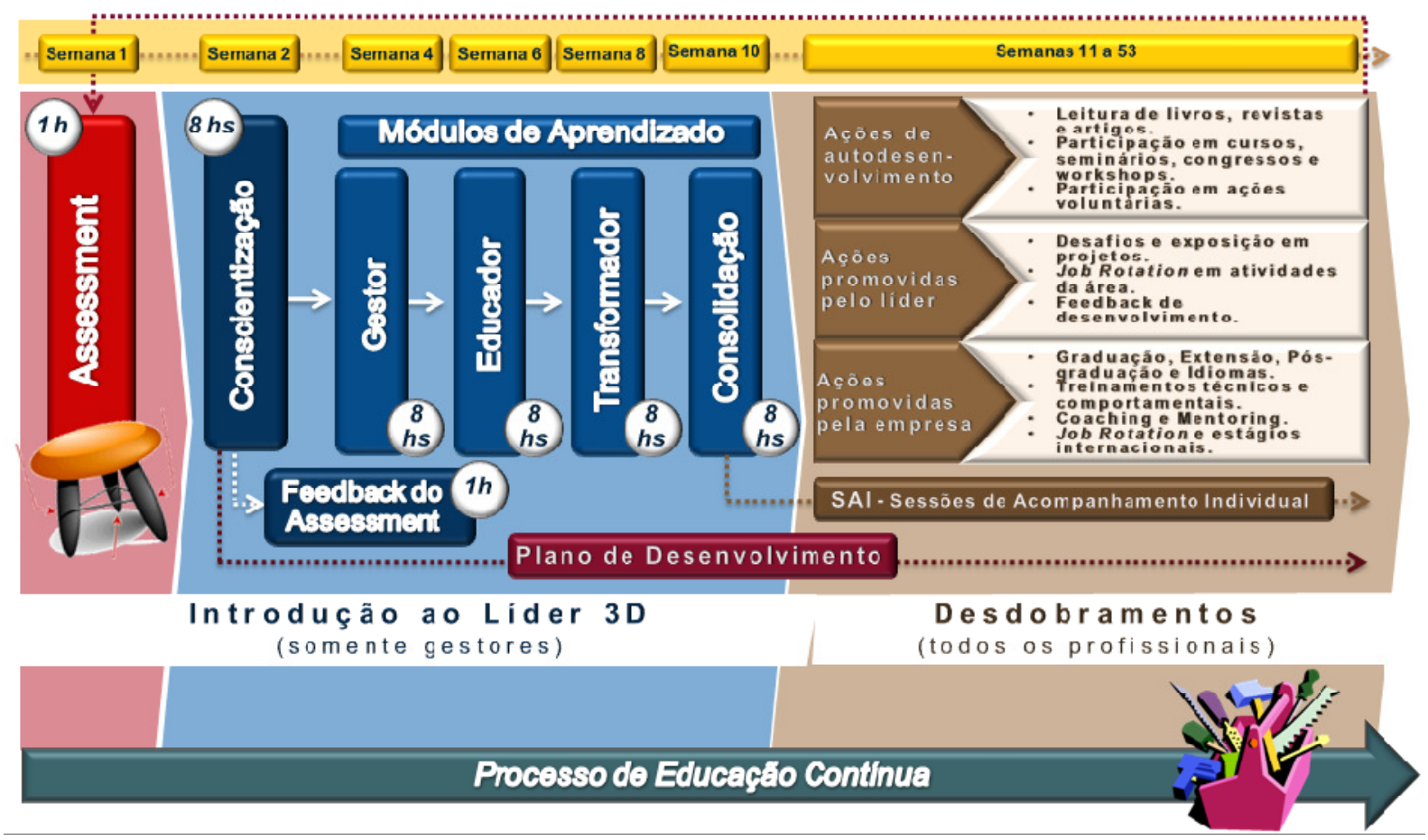


A contribuição do líder à educação corporativa e percepção de aprendizado e desenvolvimento dos empregados: o caso de uma empresa prestadora de serviços financeiros

O programa inicia-se com a realização de uma processo de avaliação $270^{\circ}$ para que os líderes possam medir sua atuação em cada uma das dimensões (Gestor, Educador e Transformador), considerando as próprias percepções, as percepções da equipe e do líder imediato. Com base nesse diagnóstico, é realizada uma sessão de feedback com uma consultoria externa, de forma a priorizar ações de desenvolvimento para os líderes.

Para a Omega, o programa Líder 3D tem entre outros objetivos preparar líderes para geração de oportunidades on the job de desenvolvimento profissional para sua equipe.

A seguir, se verificado o impacto dessas ações sobre a percepção dos empregados, analisando a relação entre a percepção do suporte da liderança ao aprendizado e desenvolvimento profissional na organização, considerando as variáveis deste estudo escolhidas no banco de dados descrito na seção de procedimentos metodológicos.

\subsection{A relação entre o suporte dos lideres no trabalho com o aprendizado e desenvolvimento na percepção dos empregados}

A média e o-desvio padrão das respostas às assertivas referentes ao suporte da liderança ao aprendizado dos empregados estão a seguir na Tabela 1. Em quase todas a média dos respondentes ultrapassou a nota 4 (concordo parcialmente), apenas as assertivas Periodicamente recebo de meu(minha) chefe avaliações sinceras sobre meu desempenho e Meu(Minha) chefe ajuda a decidir o que devo fazer para aprender mais não ultrapassaram esse valor, porém ficaram com valores próximos.a esse.

Tabela 1- Média e desvio padrão das respostas sobre o suporte das lideranças para o aprendizado dos subordinados

\begin{tabular}{|c|c|c|c|}
\hline Código & Assertiva & Média & Desvio-Padrão \\
\hline SupLid1 & Meu(Minha) chefe sempre deixa claro o que espera do meu trabalho & 4.07 & 1.05 \\
\hline & As solicitações e orientações de minha chefia facilitam a realização do meu & & \\
\hline SupLid2 & trabalho & 4.11 & 0.96 \\
\hline SupLid3 & $\begin{array}{l}\text { Periodicamente recebo de meu(minha) chefe avaliações sinceras sobre meu } \\
\text { desempenho }\end{array}$ & 3.84 & 1.20 \\
\hline & Sinto-me apoiado(a) pelo meu(minha) chefe quando decido assumir novos & & \\
\hline SupLid4 & desafios & 4.10 & 1.04 \\
\hline SupLid5 & (As) chefes sabem demonstrar como podemos contribuir com os objetivos & $\mathrm{s} 4.03$ & 1.05 \\
\hline
\end{tabular}

ReCaPe - Revista de Carreiras e Pessoas. São Paulo, V. 01, n.01 Mai/Jun/Jul/Ago 2011 


\begin{tabular}{|c|c|c|c|}
\hline & da empresa & & \\
\hline SupLid6 & Meu(Minha) chefe ajuda a decidir o que devo fazer para aprender mais & 3.83 & 1.14 \\
\hline SupLid7 & $\begin{array}{l}\text { Sou sempre bem atendido(a) quando peço orientações ao(à) meu(minha) } \\
\text { chefe }\end{array}$ & 4.21 & 0.97 \\
\hline
\end{tabular}

Quanto à média e o desvio padrão das respostas às duas assertivas referentes ao aprendizado proporcionado pelo trabalho estão a seguir na Tabela 2. Ambas também ficaram com valores próximo a nota 4 .

Tabela 2- Média e desvio padrão das respostas sobre aprendizado no trabalho

\begin{tabular}{l|l|ll}
\hline Código & \multicolumn{1}{c}{ Assertiva } & Média & Desvio-padrão \\
\hline Aprend1 & O trabalho que realizo me permite aprender coisas novas & 4.16 & 1.00 \\
& A sensação mais freqüente que sinto ao deixar o trabalho é de & & \\
Aprend2 realização profissional pelos desafios superados & 3.94 & 1.07 \\
\hline
\end{tabular}

Agora ao correlacionar as respostas de cada assertivas entre os dois grupos na Tabela 3, observa-se que quase todas as correlações apresentaram valores razoáveis, exceto as assertivas "(As) chefes sabem demonstrar como podemos contribuir com os objetivos da empresa" e "Meu(Minha) chefe ajuda a decidir o que devo fazer para aprender mais" com valores acima de $0,7,0$ que evidencia alta correlação com a assertiva "A sensação mais freqüente que sinto ao deixar o trabalho é de realização profissional pelos desafios superados".

Tabela 3- Correlações de Spearman entre as variáveis de suporte da liderança e percepção de aprendizado e desenvolvimento no trabalho

\begin{tabular}{l|lllllll} 
& \cline { 2 - 4 } & SupLid2 & SupLid3 & SupLid4 & SupLid5 & SupLid6 & SupLid7 \\
\hline Aprend1 & 0.530 & 0.542 & 0.525 & 0.518 & 0.619 & 0.657 & 0.531 \\
Aprend2 & 0.645 & 0.630 & 0.621 & 0.575 & 0.713 & 0.717 & 0.680 \\
\hline
\end{tabular}

Após analisar os resultados da percepção dos empregados tendo por contexto as iniciativas da organização em fortalecer o papel das lideranças no fornecimento do suporte à educação e desenvolvimento dos demais empregados, as considerações finais sobre o estudo serão discutidas a seguir. 
A contribuição do líder à educação corporativa e percepção de aprendizado e desenvolvimento dos empregados: o caso de uma empresa prestadora de serviços financeiros

\section{Considerações Finais}

Essa investigação teve por objetivo analisar a relação entre o papel do líder na educação corporativa e os conseqüentes impactos na percepção do empregado sobre seu aprendizado e desenvolvimento profissional. A organização objeto do estudo, a Omega, mostrou-se adequada para evidenciar essa relação, que foi constatada a partir do processo de conciliação teórica entre construtos apresentados no artigo e a base teórica utilizada seleção das afirmativas respondidas pelos empregados.

Contudo, a participação dos líderes no processo de educação corporativa não seria possível se essa organização não colocasse a figura do líder como agente principal no desenvolvimento dos seus subordinados, além de adoção um processo estruturado para desenvolvê-los.

\section{Referências}

COWAN, Stella L. Change management. In Organizational development. Info-line Collection for Training \&Performance professionals. Alexandria:ASTD, 1999.

EBOLI, Marisa. Educação Corporativa no Brasil: Mitos e Verdades. São Paulo: Editora Gente, 2004. . (org.). Universidades Corporativas - Desenvolvimento e Alinhamento dos Talentos Humanos às Estratégias Empresariais: O Surgimento da Universidade Corporativa. São Paulo: Schmukler, 1999.

GIL, A. C. Gestão de Pessoas. São Paulo: Atlas, 2001.

MEISTER, Jeanne C. Educação Corporativa - A gestão do capital intelectual através das universidades corporativas. São Paulo: Makron Books, 1999. 
MINTZBERG, Henry. Managers not MBA's: a hard look at the soft practice of managing and management development. San Francisco: 2005.

MORENO, J. Psicodrama. Tradução Alvaro Cabral. São Paulo: Cultrix, 1975.

NONAKA, I.; TAKEUCHI, H. Criação do conhecimento na empresa. São Paulo:Campos, 1997.

ODERICH, Cecilia. Gestão de competências gerenciais: noções e processo de desenvolvimento. In RUAS, Roberto. ANTONELLO, Claudia. BOFF, Luiz Henrique. Aprendizagem organizacional e competências. Porto Alegre: Bookman, 2005.

RODRIGUES DA SILVA, Maria Gorete. Coach e papéis gerenciais. In RUAS, Roberto. ANTONELLO, Claudia. BOFF, Luiz Henrique. Aprendizagem organizacional e competências. Porto Alegre: Bookman, 2005.

SCHEIN, Edgard. Organizational culture and lidership. San Francisco:Jossey Bass, 1986 Organizational culture and leadership: A dynamic view. San Francisco: Jossey-Bass, 1989.

SENGE, P. M. A quinta disciplina. São Paulo: Best Seller, 1998. . A dança das mudanças. Rio de Janeiro: Campus, 1999.

TANNEMBAUM, S. I. Enhancing continuous learning: Diagnostic findings from multiple companies. Human Resource Management, v. 36, p. 437-452, 1997.

YUKL, G. \& VAN Fleet, D. D. Theory and research on leadership in organizations. Em: Dunnette, Marvin D. \& Hough, Leaetta M. Handbook of Industrial and Organizational Psychology. (pp. 148-197). Palo Alto: Consulting Psychologists Press, 1992. 